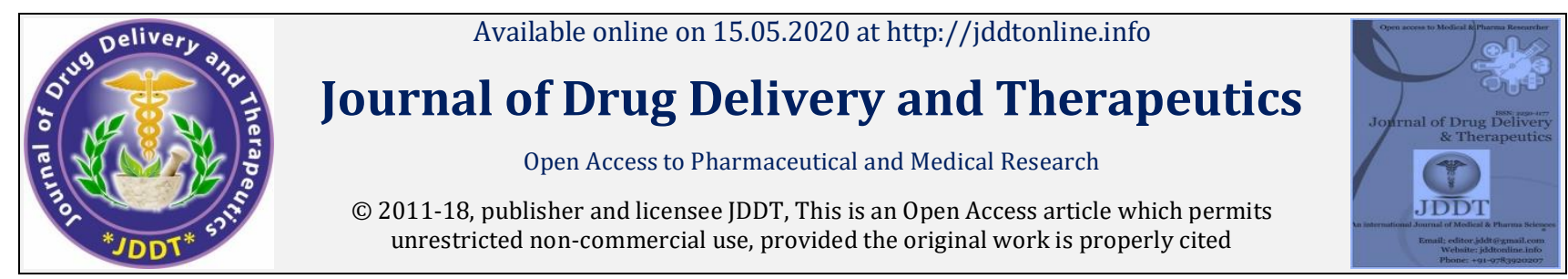

Open $\odot$ Access

Research Article

\title{
Anti-Inflammatulatory Activity of Hydro-Ethanolic Bark Extracts of Piliostigma reticulatum Hochst (Caesalpiniaceae) and Analysis by HPLC- DAD and HPLC-MS of its Methanol Fraction
}

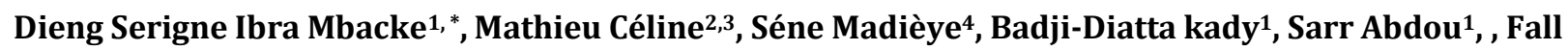 \\ Alioune Dior'1
}

\author{
${ }^{1}$ Laboratory of Pharmacognosy and Botany, Cheikh Anta Diop University, Dakar, Senegal \\ ${ }^{2}$ Laboratory of Agro-Industrial Chemistry, LCA, University of Toulouse, INRA, Toulouse, France \\ ${ }^{3}$ Center of Application and Treatment of Agro-Ressources (CATAR), INP, Toulouse, France \\ ${ }^{4}$ Laboratory of Pharmacology and Pharmacodynamic, Cheikh Anta Diop University, Dakar, Senegal
}

\begin{abstract}
Use of plants as remedies dates back to the time of the oldest civilizations. Among these active ingredients, polyphenols play an important role. Piliostigma reticulatum, a plant whose barks are rich in condensed tannin is often used as an anti-inflammatory. The purpose of this work was to correlate the anti-inflammatory activity of extracts with their chemical composition through chromatography fractionation analyses (HPLCDAD and HPLC-MS). The barks were extracted by moderate hydroethanol decoction followed by silica gel splitting with successively ethyl acetate, methanol and water. Anti-inflammatory activity was evaluated by the method of carrageenan induced hind paw edema in Wistar rats. The chemical study was carried out by HPLC-DAD and HPLC-MS after isolation of the compounds by fractionation on Sephadex LH-20 gel. The bark hydroethanolic extract had shown ability to inhibit significantly the inflammation induced by carraghenan. Among the hydroethanolic bark extract fractions that methanol fraction had the best activity at $10 \mathrm{mg} / \mathrm{kg}$ with inhibition percentages similar to those of acetylsalicylic acid with $48.51 \% \pm 2.26 ; 54.71 \% \pm 5.13 ; 64.19 \% \pm 6.70$ vs. $54.69 \% \pm 7.23 ; 57.83 \% \pm 9 ; 65.13 \% \pm 8.44$ respectively. The HPLC-DAD analysis showed that the SF5 sub-fraction presented the best chromatogram with several peaks, three of which were high intensity. The latter would correspond to monomer, dimer and trimer of catechin according to the weights [M-H] + m / z: 291.07; 579.18; 867.27 obtained by HPLC-MS. The compounds responsible for anti-inflammatory activity would be condensed tannins. The latter would consist mainly of catechin oligomers.
\end{abstract}

Keywords: Piliostigma reticulatum, bark, anti-inflammatory activity, HPLC-DAD, HPLC-MS

Article Info: Received 07 March 2020; Review Completed 12 April 2020; Accepted 22 April 2020; Available online 15 May 2020

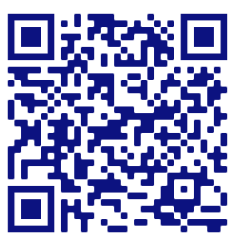

Cite this article as:

Dieng SIM, Mathieu C, Séne M, Badji-Diatta K, Sarr A, Fall AD, Anti-Inflammatulatory Activity of Hydro-Ethanolic Bark Extracts of Piliostigma reticulatum Hochst (Caesalpiniaceae) and Analysis by HPLC-DAD and HPLC-MS of its Methanol Fraction, Journal of Drug Delivery and Therapeutics. 2020; 10(3):97-106 http://dx.doi.org/10.22270/jddt.v10i3.4058

Dieng Serigne Ibra Mbacke, Laboratory of Pharmacognosy and Botany, Cheikh Anta Diop University, Dakar, Senegal.

\section{INTRODUCTION}

The use of plants as remedies originates in the oldest civilizations. To this day, despite considerable advances in modern medicine and the pharmaceutical industry, medicinal plants still remain important in the medical care of populations. Pharmacies and pharmaceutical industries continue to use them in dried form or as raw materials for the manufacture of medicines. Au Sénégal, les plantes médicinales sont très présentes dans les marchés urbains et constituent semble-t-il la principale source d'automédication des populations. This is certainly due to the many pharmacological properties granted to plants but also to the cost well accessible to the population. In recent years, there have been numerous studies to justify the use of plant-based products to prevent or treat certain diseases by using pharmacological tests and identification of the active ingredients responsible for their effect.

Among these active ingredients, the polyphenol family occupies an important place. They are believed to be responsible of many related biological activities of plants such as anti-inflammatory, antimicrobial, antiradical activities [1]. Polyphenols are known to be excellent antioxidants especially through their ability to trap free radicals responsible for oxidative stress [2],3]. They prevent diseases that are often associated with them such as cancer, coronary heart disease, thrombosis, osteoarthritis, atherosclerosis and aging [4,5]. This is the case for phenolic compounds such as anthocyanins, flavonols, catechin etc.[6]. 
In addition, the barks of Piliostigma reticulatum (DC) Hochst (Caesalpiniaceae; Synonym: Bauhinia reticulata) are very rich in polyphenols made up mainly of condensed tannins [7]. This is how we became interested in the evaluation of antiinflammatory activity as well as the study of the nature of the tannins of its barks. Piliostigma reticulatum is a wellknown plant of Senegalese traditional practitioners who use the bark of the plant to treat toothache, gingivitis, diarrhea and over-infected wounds $[8,9,10]$.

The objective of this work was to correlate the antiinflammatory activity of extracts with their chemical composition through fractional analyses by chromatography (HPLC-DAD and HPLC-MS).

\section{MATERIAL AND METHODS}

\section{Plant material}

The barks of Piliostigma reticulatum were harvested in Diourbel, central Senegal. The plant has been identified at the Pharmacognosy and Botany Laboratory of the Medicine, Pharmacy and Odontology Faculty of the Cheikh Anta Diop University in Dakar. The identification herbarium number of this plant is 1641 . The barks were washed for about 15 minutes with tap water and then dried at room temperature for two weeks in the dark and in an airy room of the laboratory before being reduced to powder by a grinder (Brabender®, granulometry : $1.5 \mathrm{~mm}$ ). The powder was used for extraction.

\section{Animals}

Adult male and female Wistar rats (160 to $220 \mathrm{~g}$ ) were used to assess anti-inflammatory activity. Male and females rats were raised separately in the pet shop of the Laboratory of Pharmacology of the Faculty of Medicine, Pharmacy and Odontology. They had free access to food and water until $16 \mathrm{~h}$ before the experiments.

\section{Reagents and solvents}

The solvents and reagents that have been used are: Ethanol (VWR Chemicals BDH, France), Methanol (Carlo ERBA, France), Ethyl acetate (VWR Chemicals BDH, France), distilled water, silica gel (Scharlau GE 0048,60A- 0.04-0.06 $\mathrm{mm}$ ), Carrageenan (Sigma Aldrich, Allemagne), acetyl salicylic acid (Sigma Aldrich, Chine),physiological water 0,9\%, Sephadex LH-20 (Sigma-Aldrich, USA), silica CCM plates (TLC Silica gel - $F_{254}$, Merck), formic acid (VWR Chemicals BDH, France), aluminum silica plates (TLC Silica gel - F 254, Merck).

\section{Extraction}

The hydroethanol extract (HEE) of the barks was obtained by moderate decoction under reflux of the powder at about $70^{\circ} \mathrm{C}$ for 30 minutes. Thus $600 \mathrm{~g}(4 \times 150 \mathrm{~g})$ of powder was extracted with 6 liters $(4 \times 1.5 \mathrm{~L})$ of ethanol-water mixture $\mathrm{v} / \mathrm{v}(80: 20)$. After cooling and filtration on Whatman No 1 filter paper, the solvent was removed using a rotary evaporator at $60^{\circ} \mathrm{C}$. The resulting dry extract was powdered and sealed in a jar.

\section{Silica column fractionation}

The fractionation was done by adapting the method of Labourel and Péaud-Lenoel [11]. A cylindrical glass column 3 $\mathrm{cm}$ in diameter was filled with $100 \mathrm{~g}$ of silica mixed with 300 $\mathrm{ml}$ of ethyl acetate while avoiding trapping air. The silica was then washed three times in a row with $200 \mathrm{ml}$ of ethyl acetate generating a separation height of $31 \mathrm{~cm}$ with a dead volume of $195 \mathrm{ml}$. Then $2 \mathrm{~g}$ of powdered hydroethanol bark extract and $2 \mathrm{~g}$ of silica homogeneously mixed by triturating with methanol before evaporating it in the boil at $40^{\circ} \mathrm{C}$, were deposited at the head of the column so that the surface was horizontal, then protected with cotton to avoid depressions caused by elution. Elution was made with successively $0.5 \mathrm{~L}$ of ethyl acetate, $0.5 \mathrm{~L}$ of methanol and 0.5 $\mathrm{L}$ of Milli-Q water with an average flow of $12.3 \mathrm{ml} / \mathrm{min}$. The dead volume was eliminated after each change of solvent. The three fractions thus collected (Methanol Fraction, FM; Ethyl acetate fraction, FAE; Water Fraction, FA) have been evaporated and dried by the same process as the EHH previously described.

\section{Sephadex LH-20 column fractionation}

A Sephadex LH-20 fractionation of the methanol fraction was carried out using the slightly modified method described by Yang et al. [12]. A $3 \mathrm{~cm}$ diameter glass cylindrical column was carefully filled with $20 \mathrm{~g}$ of Sephadex LH-20 gel mixed with $200 \mathrm{ml}$ of methanol while avoiding any trapping air. The column was then washed twice in a row with $200 \mathrm{ml}$ of methanol. Elution was made with a solvent system water/methanol of different proportions (100/0; $70 / 30 ; 50 / 50 ; 20 / 80 ; 0 / 100, v / v)$. The eluent was collected in test tubes at a volume of about $5 \mathrm{ml}$ per tube at a rate of one drop per second.

At the end of the elution, all test tubes were analyzed by Thin Layer Chromatography (TLC) with the Methanol/Ethyl Acetate/Hexane mixture as a migration solvent (2/1/1.5, $\mathrm{v} / \mathrm{v})$. The revelation was made with sulphuric vanillin $(0.1 \mathrm{~g}$ of vanillin - $28 \mathrm{ml}$ of methanol $-1 \mathrm{ml}$ of $\mathrm{H}_{2} \mathrm{SO}_{4}$ ). The tubes having the same profile were combined leading thus to six sub-fractions named SF1 to SF6.

\section{Anti-inflammatory activity}

The anti-inflammatory activity of the bark extract and its fractions was evaluated by the method of rat hind paw edema induced by carrageenan $[13,14]$.

Rats were divided into 5 lots of 5 each: one group per dose administered and fasted 16 hours before the experiment. The extracts were prepared with physiological water and administered by gavage at different doses:

- Lot 1 (control): physiological water $(10 \mathrm{ml} / \mathrm{kg}$, per os);

- Lot 2 (reference): acetylsalicylic acid (10 mg/kg, per os) ;

- Lot 3 and 4: hydroethanol extract (100 and $300 \mathrm{mg} / \mathrm{kg}$, peros) ;

- Lot 5: fractions from hydroethanol extract $(1 \mathrm{mg} / \mathrm{kg}$, per os);

- Lot 6: fractions from hydroethanol extract (3 mg/kg, per os);

- Lot 7: fractions from hydroethanol extract $(10 \mathrm{mg} / \mathrm{kg}$, peros).

An edema under the plantar pad of the rats' right paw was induced by injection of $100 \mu \mathrm{l}$ of a $1 \%$ carrageenan solution $(\mathrm{m} / \mathrm{v}) 1$ hour after feeding the rats. The thickness of the leg was measured before the induction of the edema and then at 1,3 and 5 hours after induction using an electronic calliper.

The importance of edema was appreciated by determining the average percentage increase (\% API) in the thickness of the rat leg following the formula:

$$
\% A P I=\frac{T R h-T R 0}{T R 0} \times 100
$$

$\mathrm{TRh}$ : Thickness of rat's paw at T-time

TR0 : Thickness of the rat's paw at 0 -time 
The anti-inflammatory activity of the samples was expressed as a percentage of edema inhibition (\% INH) calculated according to the following formula:

$$
\% I N H=\frac{\% \text { APIcontrol }-\% \text { APIsample }}{\% \text { APIcontrol }} \times 100
$$

\section{HPLC-DAD analysis of Subfraction (SF1 to SF6)}

The tests were carried out on an Ultimate 3000 (Thermofisher) chain equipped with an automatic injector, a thermostatized compartment at $35^{\circ} \mathrm{C}$ and a UV-DAD detector. The samples were prepared by dissolution or dilution in the HPLC grade methanol. All samples were filtered on $0.22 \mu \mathrm{m}$ PTFE membrane. The extracts and the standard (catechin) were injected due to $10 \mu \mathrm{l}$ per sample. Chromatographic separation was obtained at $40^{\circ} \mathrm{C}$ on an C18 reverse phase column (Luna 3u PFP (2) 100A ; 150x3.0 mm (Phenomenex)) preceded by a pre-column. Elution was made under pressure between 112 -145 bars with a flow of $0.3 \mathrm{~mL} / \mathrm{min}$ of the moving phase according to a gradient mentioned on Table 1 . The moving phase was composed of a mixture of solvent A $(0.1 \%$ solution of formic acid in MilliQ water) and solvent B (a solution of $0.1 \%$ formic acid in HPLC grade methanol). The detection of separate compounds was made at $254 \mathrm{~nm}$ and $280 \mathrm{~nm}$.

Table 1 : Gradient of elution of the mobile phase of the samples

\begin{tabular}{cccc}
\hline Time (min) & Water 0,1\% formic acid & Methanol 0,1\% formic acid & Flow (ml/min) \\
\hline 0 & 85 & 15 & 0.3 \\
\hline 15 & 80 & 20 & 0.3 \\
\hline 35 & 60 & 40 & 0.3 \\
\hline 40 & 35 & 65 & 0.3 \\
\hline 45 & 30 & 70 & 0.3 \\
\hline 50 & 30 & 70 & 0.3 \\
\hline 51 & 85 & 15 & 0.3 \\
\hline 55 & 85 & 15 & 0.3
\end{tabular}

The treatment of chromatograms was carried out by Chromeleon 6.8 software.

\section{HPLC-MS analysis of the Subfraction SF5}

The analyses were carried out on a chain of HPLC Ultimate 3000 (Thermofisher Scientiific) coupled with mass spectrometry (Bruker HPL071) in positive ionization mode. This series-connected chain is equipped with a UV detector and an Amazon SL ion trap mass detector with an electropray ionization interface (ESI). The extract was prepared by dissolution in the HPLC grade methanol of the dry extract of subfraction SF5. The resulting solution was filtered on $0.22 \mu \mathrm{m}$ PTFE membrane before injection. The chromatographic separation was obtained on Kinetec EVo C18 column (150x2,1 mm, 2,6 $\mu \mathrm{m}$, Phenomenex) at a flow of $0.3 \mathrm{ml} / \mathrm{min}$ at $35^{\circ} \mathrm{C}$, with UV detection at 250,280 and 330 $\mathrm{nm}$ for mass with spectrum recording from 50 to $2000 \mathrm{~m} / \mathrm{z}$. The voltage of the capillary of the ESI source is adjusted to $4.5 \mathrm{KV}$. The pressure of the nebulizer was set at $40 \mathrm{psi}$ nitrogen. For desolvation, the temperature was $200^{\circ} \mathrm{C}$ and the gas had a flow of $9 \mathrm{l} / \mathrm{min}$. The elution gradient was identical to that used for HPLC-DAD and data processing was carried out with Hystar and Data analysis software.

\section{Statistical analyses}

The data were expressed as average \pm SEM. The significative analyses was carried out by Fisher's test using StatView version 4.55 software. A value of $p<0.05$ was considered to be statistically significant.

\section{RESULTS}

\section{Extraction and fractionation}

From $600 \mathrm{~g}$ of bark powder, $70 \mathrm{~g}$ of dry hydroethanolic extract were obtained representing a yield of $11.66 \%$. Silica gel fractionation of $2 \mathrm{~g}$ of hydroethanolic extract gave the fractionation yields mentioned in Table 2 .

Table 2 : Yields of ethyl acetate, methanol and aqueous fractions

\begin{tabular}{lccc}
\cline { 2 - 4 } & EAF & MF & AF \\
\hline Dry extract (g) & 0.044 & 1.616 & 0.209 \\
\hline Yield (n: 3 ; \%) & $2.19 \pm 0.1$ & $80.80 \pm 3.3$ & $10.47 \pm 0.13$ \\
\hline EAF: Ethyl acetate fraction, MF: Methanol Fraction ; AF: Aqueous \\
fraction
\end{tabular}

\section{Anti-inflammatory activity}

The evaluation of the inhibition of increased edema induced by bark hydroethanol extract (HEE) yielded the results illustrated by Fig. 1. Compared to the control lot, HEE caused a dose-dependent inhibition of the induced inflammation. At the dose of $100 \mathrm{mg} / \mathrm{kg}$, inhibition of increased edema was not significant except for the 5th hour $(41.36 \% \pm 6.69$; $67.16 \% \pm 3.76 ; 64.09 \% \pm 2.71$ respectively at $1 \mathrm{~h}, 3 \mathrm{~h}$ and $5 \mathrm{~h}$ ) with inhibition percentages (\%INH) corresponding to $13.73 \% \pm 10.2 ; 17.19 \% \pm 5.84 ; 29.42 \% \pm 4.61$. However, at $300 \mathrm{mg} / \mathrm{kg}$, HEE inhibits significantly manner the increase inflammatory edema at every hour with $11.05 \% \pm 1.84$; $44.66 \% \pm 5.62$ and $62.23 \% \pm 2.9$ respectively at $1 \mathrm{~h}, 3 \mathrm{~h}$ and $5 \mathrm{~h}$. The inhibition percentages of inflammation obtained at this dose were $77.01 \% \pm 4.71 ; 44.74 \% \pm 8.01 ; 31.10 \% \pm 6.25$ respectively at $1 \mathrm{~h}, 3 \mathrm{~h}$ and $5 \mathrm{~h}$. 


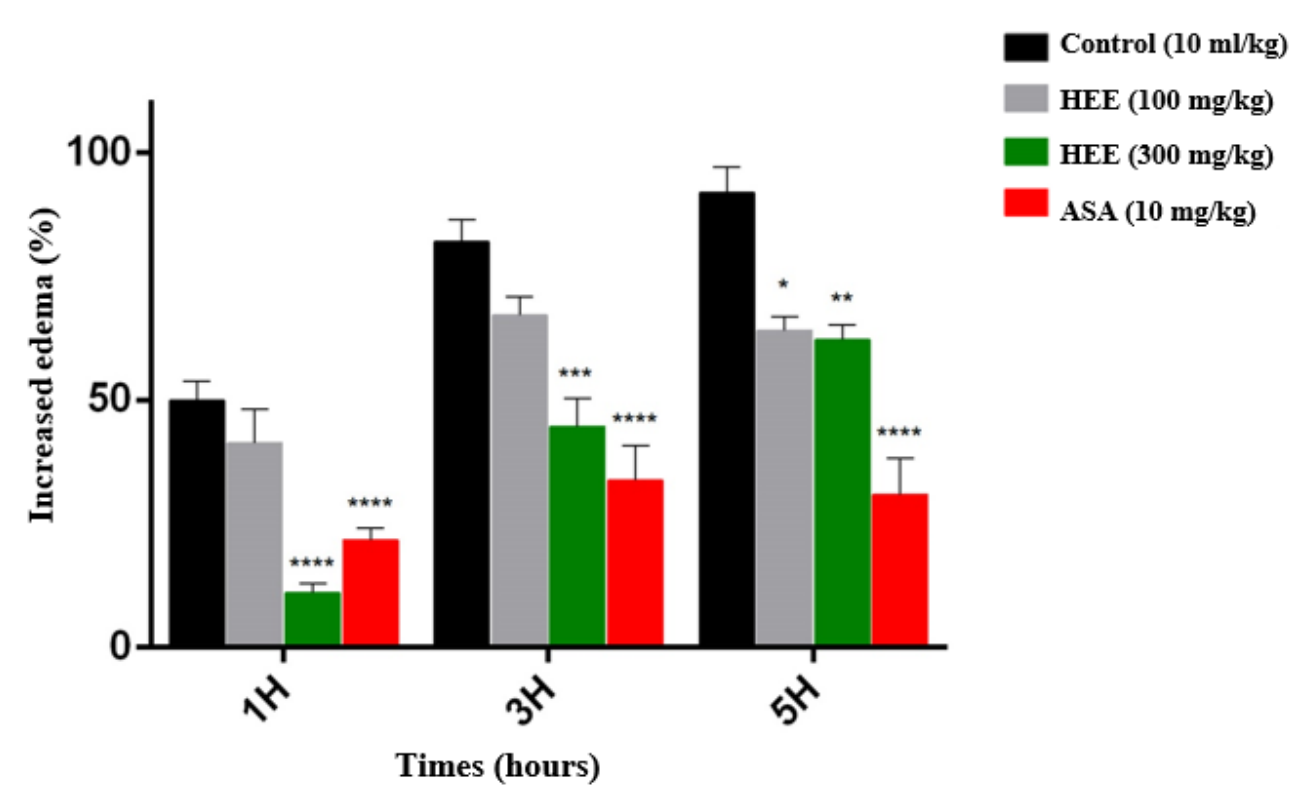

Fig. 1 : Inhibition of increased inflammatory edema by bark hydroethanol extract at different doses and acetylsalicylic acid.

HEE : Hydroethanol extract; ASA : Acetylsalicylic acid; * $p<0.05$

The fractions also showed dose-dependent activity. Of all the fractions from EHE, the methanol fraction at the $10 \mathrm{mg} / \mathrm{kg}$ dose is the most active. The variation in the inflammatory edema which it induced was $25.62 \% \pm 2.11 ; 36.36 \% \pm 2.28$ and $31.62 \% \pm 3.88$ respectively at $1 \mathrm{~h}, 3 \mathrm{~h}$ and $5 \mathrm{~h}$ (see Fig. 2 ). At this dose, its activity was statistically similar to that of the reference, acetylsalicylic acid (21.79 \pm 2.27 at $1 \mathrm{~h} ; 33.77 \pm$ 7.08 at $3 \mathrm{~h} ; 30.96 \pm 7.25$ at $5 \mathrm{~h}$ ) as shown in Fig. 3 .
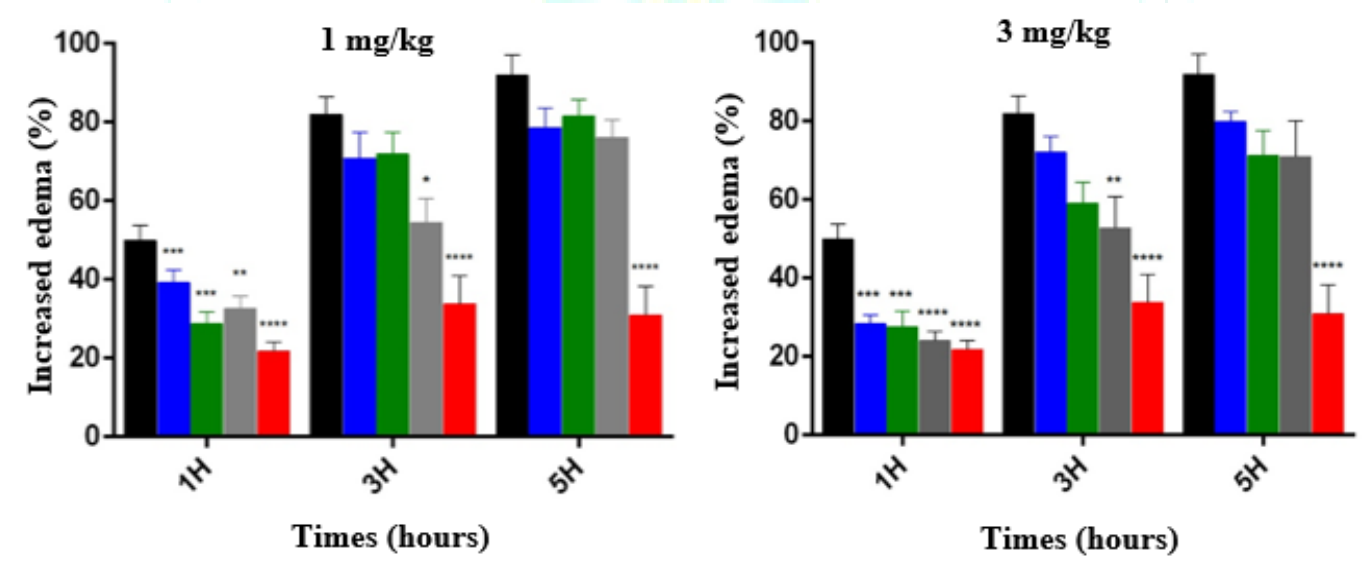

|

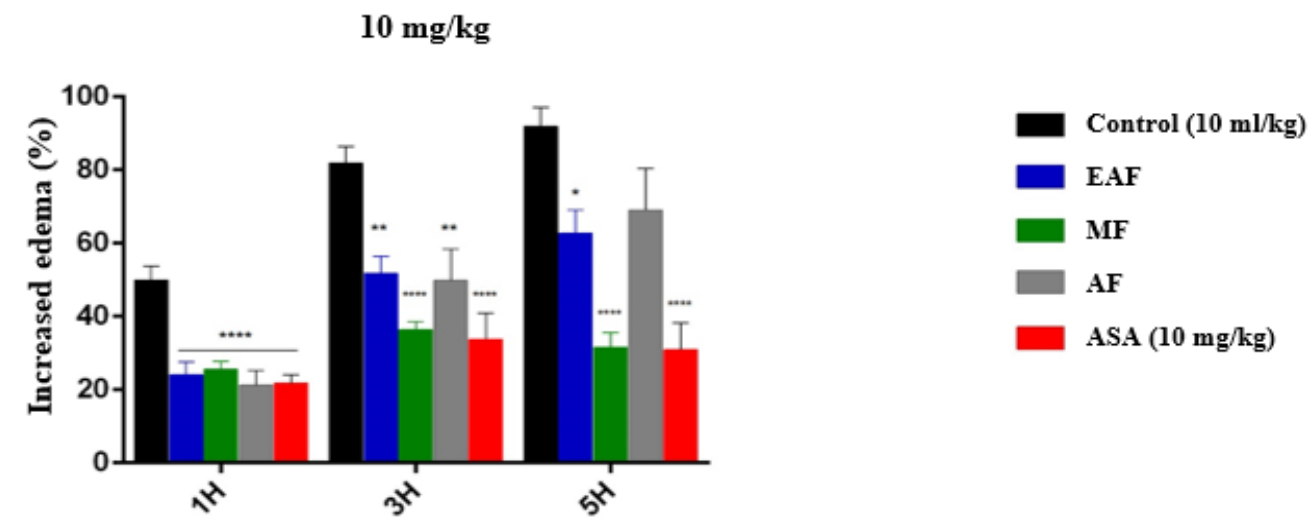

Times (hours)

Fig. 2 : Inhibition of increased inflammatory edema by fractions of bark hydroethanol extract at different doses and by acetylsalicylic acid.

EAF: Ethyl acetate fraction ; MF: Methanol Fraction; AF: Aqueous fraction; ASA : Acetylsalicylic acid ; * : p $<0.05$ 


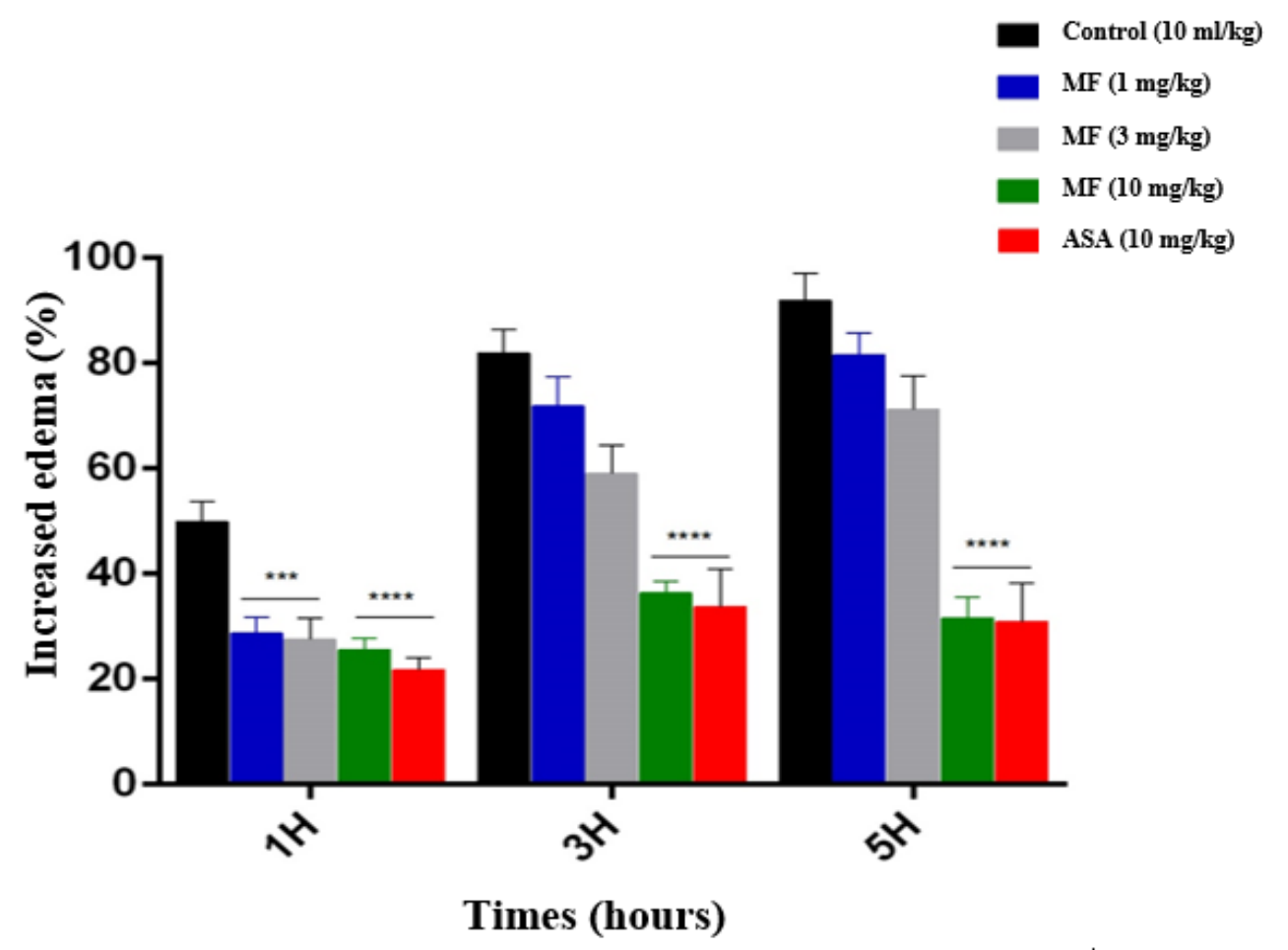

Fig. 3 : Inhibition of increased edema by methanol fraction at different doses and acetylsalicylic acid at $10 \mathrm{mg} / \mathrm{kg}$ MF: Methanol Fraction ; ASA : Acetylsalicylic acid; * $\mathrm{p}<0.05$

The inhibition percentages of inflammation of methanol fraction and acetylsalicylic acid at $10 \mathrm{mg} / \mathrm{kg}$ were $48.51 \%$ 2.26, respectively; $54.71 \%-5.13 ; 64.19 \%-6.70$ versus $54.69 \%-7.23 ; 57.83 \%-9 ; 65.13 \%-8.44(p<0.05$ every hour).

\section{HPLC-DAD analysis of subfractions (SF1 to SF6)}

The resulting chromatograms showed the most important UV absorption at $280 \mathrm{~nm}$. Of all the samples injected, the SF5 had the most complex chromatographic profile with the presence of several peaks, among which three had a high absorption: peak 3,5 and 6 (see figure 3). The chromatogram data are summarized in table 3.

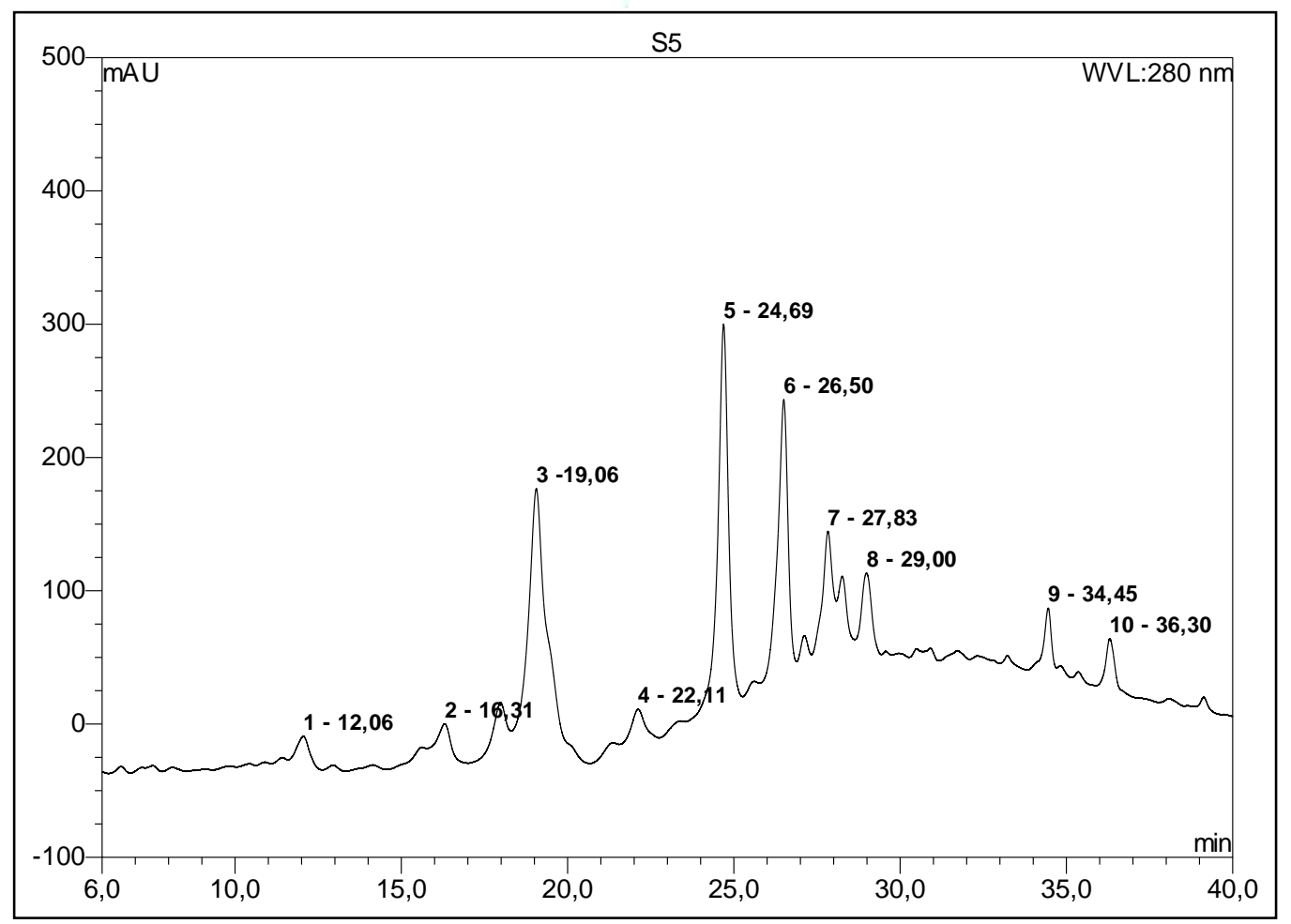

Fig. 4 : SF5 Chromatogram obtained by HPLC-DAD analysis 
Table 3 : SF5 HPLC-DAD chromatogram data

\begin{tabular}{ccccc}
\hline No. peak & $\begin{array}{c}\text { Ret.Time } \\
\text { min }\end{array}$ & $\begin{array}{c}\text { Height } \\
\text { mAU }\end{array}$ & $\begin{array}{c}\text { Area } \\
\text { mAU*min }\end{array}$ & $\begin{array}{c}\text { Rel.Area } \\
\text { \% }\end{array}$ \\
\hline 1 & 12.06 & 24.712 & 14.822 & 3.69 \\
2 & 16.31 & 29.363 & 19.873 & 4.94 \\
3 & 19.06 & 189.198 & 113.805 & 28.31 \\
4 & 22.11 & 24.112 & 10.683 & 2.66 \\
5 & 24.69 & 292.212 & 112.825 & 28.06 \\
6 & 26.50 & 210.588 & 77.611 & 19.30 \\
7 & 27.83 & 58.743 & 14.872 & 3.70 \\
8 & 29.00 & 55.037 & 17.862 & 4.44 \\
9 & 34.45 & 42.886 & 9.449 & 2.35 \\
10 & 36.30 & 36.396 & 10.245 & 2.55 \\
Total: & & 963.247 & 402.049 & 100.00 \\
\hline
\end{tabular}

Peak 3 at a retention time of 19.06 min could correspond to the catechin as shown by the overlay of the two chromatograms (see fig. 5).

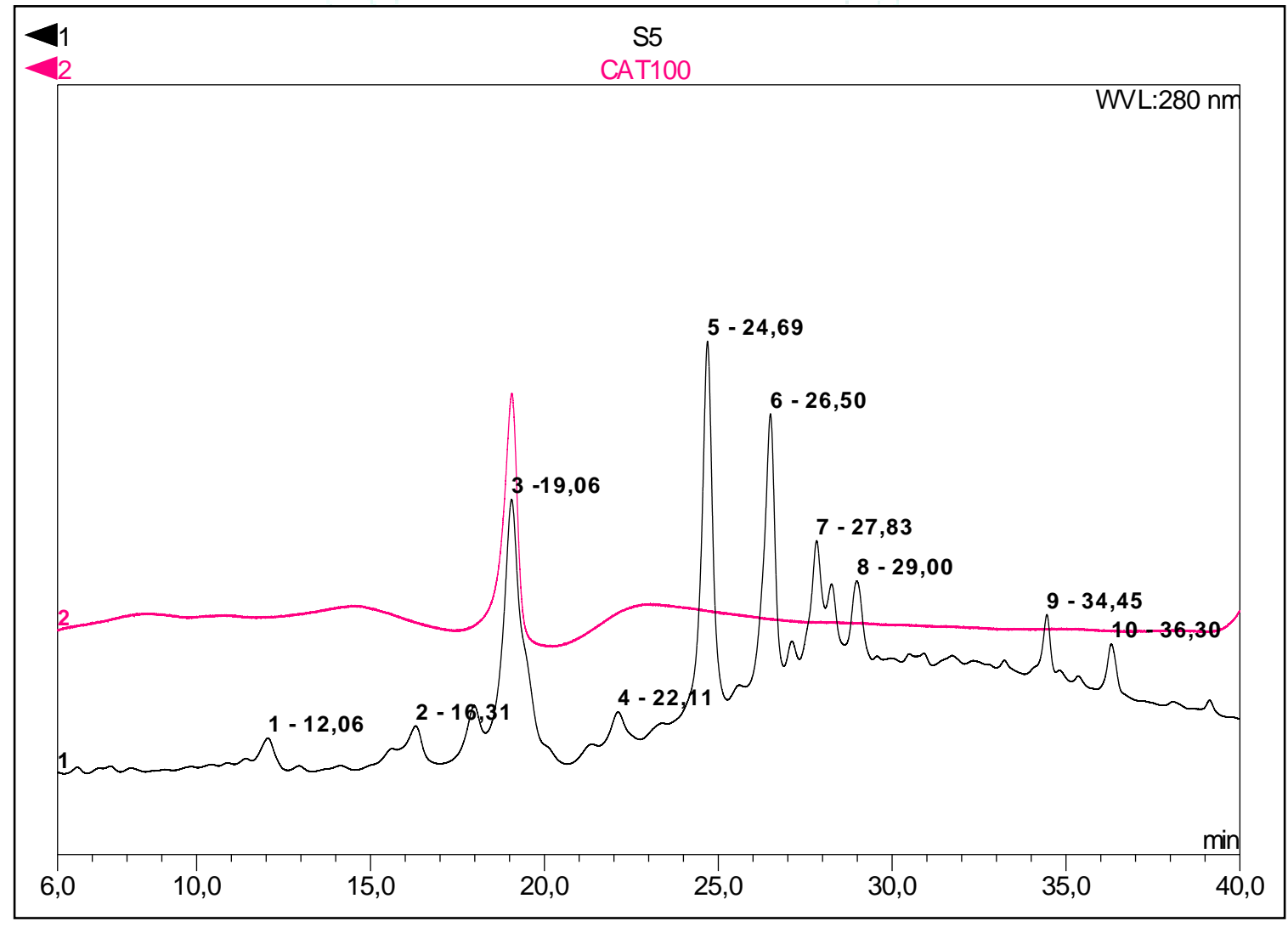

Fig. 5 : Chromatogrammes HPLC-DAD de la SF5 (1) et de la catéchine (2) 


\section{HPLC-MS Analysis of SF5}

Positive ionization made it possible to obtain molecular ions $[\mathrm{M}+\mathrm{H}]+$. The resulting chromatograms yielded several molecular ion weights $(\mathrm{m} / \mathrm{z})$ of which 3 were frequently present with a high signal/noise ratio $(\mathrm{S} / \mathrm{N})$ as shown in fig. 6. Mass spectrum data was summarized in table 5.
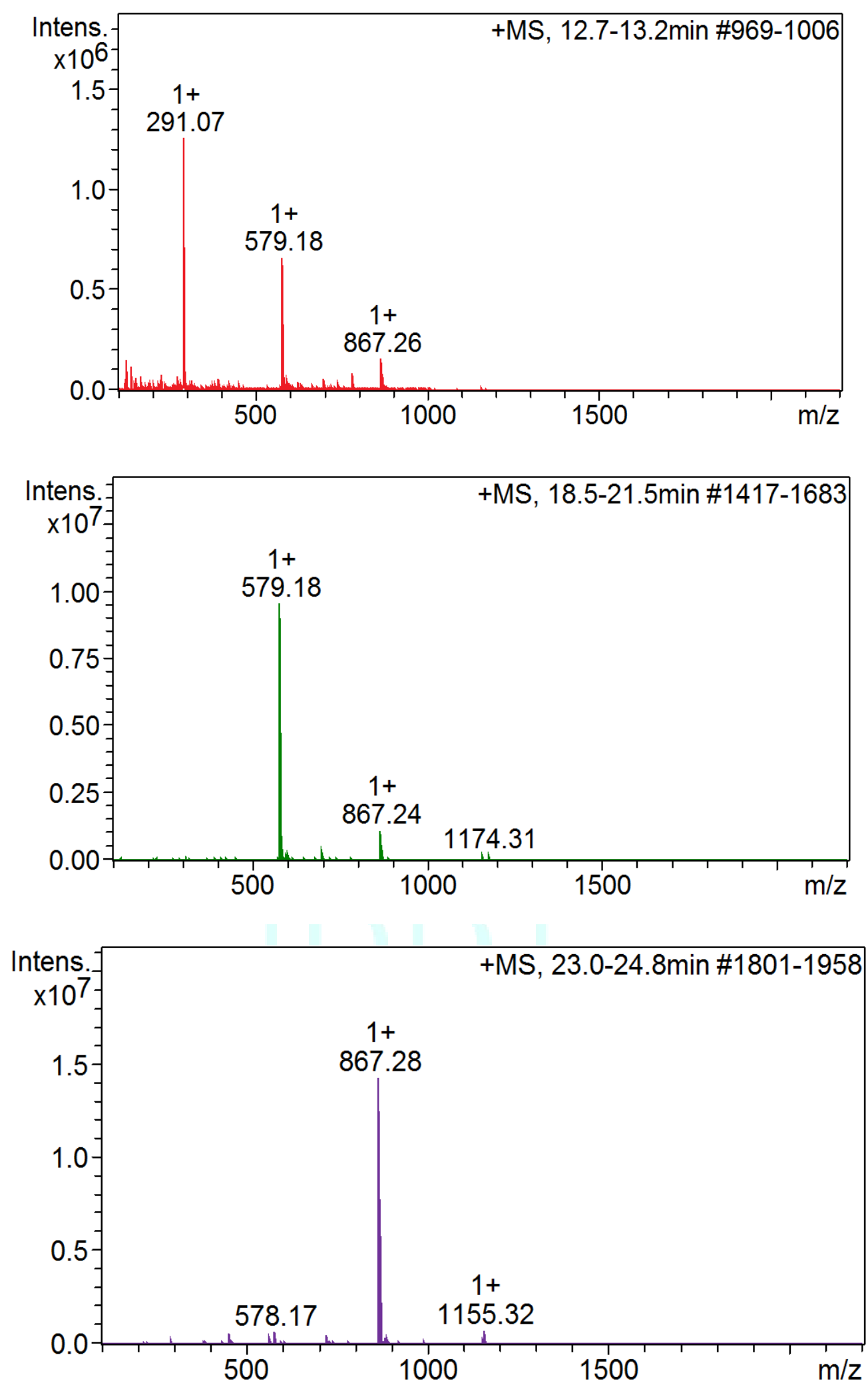

Fig. 6 : HPLC-MS chromatogram at different retention times of SF5 
Table 4 : HPLC-MS spectrum data of SF5

\begin{tabular}{cccccc}
\hline Tr (min) & {$[\mathbf{M}-\mathbf{H}] \mathbf{~ m} / \mathbf{z}$} & $\mathbf{z}$ & $\mathbf{I}$ & $\mathbf{F W H M}$ & $\mathbf{S} / \mathbf{N}$ \\
\hline 2.6 & 330.20 & $1+$ & 1022309 & 0.39 & 401.9 \\
5.2 & 577.18 & $1+$ & 281895 & 0.43 & 143.1 \\
9.4 & 453.18 & $1+$ & 356798 & 0.43 & 137.8 \\
9.9 & 741.24 & $1+$ & 443343 & 0.42 & 195.7 \\
12.8 & 291.08 & $1+$ & 1257750 & 0.38 & 500.5 \\
14.4 & 579.19 & $1+$ & 1364623 & 0.42 & 576.6 \\
17.8 & 867.24 & $1+$ & 414503 & 0.42 & 188.6 \\
21.0 & 579.19 & $1+$ & 12309845 & 0.42 & 2601.3 \\
22.0 & 291.08 & $1+$ & 3038763 & 0.39 & 654.7 \\
22.5 & 865.27 & $1+$ & 1178800 & 0.42 & 268.0 \\
23.7 & 867.28 & $1+$ & 14312367 & 0.44 & 2411 \\
24.2 & 1155.32 & $1+$ & 1776091 & 0.46 & 307.1 \\
25.0 & 772.21 & $1+$ & 1824975 & 0.29 & 266.0 \\
26.3 & 520.39 & $1+$ & 7209310 & 0.41 & 721.5 \\
28.4 & 652.47 & $1+$ & 6857386 & 0.43 & 607.4 \\
30.0 & 428.32 & $2+$ & 968002 & 0.31 & 56.8 \\
36.0 & 313.33 & $1+$ & 7199566 & 0.42 & 156.5 \\
\hline
\end{tabular}

Tr : Retention time ; Z : Proton number $\quad$; I : Intensité ; FWHM : Full width at half maximum ; S/N : Signal/Noise ratio

\section{DISCUSSION}

Hydroethanol bark extract showed, at high dose $(300$ $\mathrm{mg} / \mathrm{kg}$ ) and at a short period of time, a significant antiinflammatory activity greater even than that of acetylsalicylic acid, but this activity decreased in intensity over time. On the other hand, it inhibited in a dosedependent manner induced inflammation since a decrease of the administered dose resulted in a sharp decrease of antiinflammatory activity with inhibition percentages (IP) less than $30 \%$ every hour.

At all doses tested, the fractions inhibited induced inflammation in a dose-dependent manner from 1 to 10 $\mathrm{mg} / \mathrm{kg}$. Unlike hydroethanol extract, fractions showed lowdose activity with $10 \mathrm{mg} / \mathrm{kg}$ as the maximum active dose. The fractionation therefore appeared to increase the antiinflammatory effect of the extract.

Of all the fractions tested, the methanol was the most active and inhibited in long time manner the induced inflammation at $10 \mathrm{mg} / \mathrm{kg}$ with IP greater than $50 \%$ at all times. Its activity has been statistically similar to that of acetylsalicylic acid, Which suggesting on the one hand that they have the same mechanism of action. On the other hand, the active compounds responsible for the anti-inflammatory activity of the barks extract have a greater affinity for methanol than for other solvents. This has been the case with the work of Nariman et al.[15] where silica column fractionation showed that the methanol fraction contained the active biological compounds responsible for the antibacterial activity of the aerial parts of Xanthium brasilicum and Trachyspermum copticum. This seems to be confirmed by the fractionation yields that were obtained with $80.80 \%$ for the methanol fraction.

As a result, the methanol fraction was split again on Sephadex LH-20 gel in order to isolate and identify the active compounds responsible for its anti-inflammatory activity. In addition, our previous results showed that the barks of the plant were composed mainly of condensed tannins (72.18\%) and that more than $56 \%$ of these tannins were isolated by fractionation with methanol [7]. These condensed tannins appeared to be the support of the biological activity of the barks. These were flavan-3-ols polymers (proanthocyanidols) subdivided into several subgroups. The most common was the subgroup of procyanidines where the constituent unit is most often catechin or epicatechin. They have been isolated and identified in all plant families [16,17,18]. This justifies the use of catechin as standard for this study. The Sephadex LH-20 is a hydroxypropyled and reticulated dextran gel with an average diameter of dry beads 18-111 $\mu \mathrm{m}$. The latter swell in methanol to give diameters between 27-163 $\mu \mathrm{m}$. It is used to isolate polyphenolic molecules such as flavanolic monomers as well as oligomers such as dimers, trimers or even tetramers $[19,20]$.

The chromatogram obtained by HPLC-DAD analysis of the SF5 showed the presence of several compounds, three of which had a maximum absorption corresponding to peak 3 : 189,198 mAU respectively; peak 5: 292,212 mAU and peak 6: $210,598 \mathrm{mAU}$. The overlay of this chromatogram with that of the catechin showed that peak 3 had the same retention time as the standard. This suggests that the SF5 contained catechin that would correspond to peak 3 (see fig. 7). This was confirmed by the mass spectrum of SF5 where high-intensity peaks were found with molecular ion weights $[\mathrm{M}-\mathrm{H}]^{+} \mathrm{m} / \mathrm{z}: 291.07 ; 579.18 ; 867.27$ representing the molecular mass of monomer, dimer and trimer of catechin respectively (m/z: $290 \mathrm{~g} / \mathrm{mol} ; 578 \mathrm{~g} / \mathrm{mol}$ and $866 \mathrm{~g} / \mathrm{mol})$. However, it was found that these same weights $[\mathrm{M}-\mathrm{H}]+\mathrm{m} / \mathrm{z}$ were found several times at different retention times. It would be due to the presence of an isomer of catechin namely epicatechin. This could lead to several types of oligomers such as for exemple dimers of epicatechin, catechin-epicatechin; trimers of epicatechins, catechinepicatechin-catechin, catechin-catechechin, epicatechinepicatechin-catechin, epicatechin-catechin- epicatechin. Low intensity peaks of $\mathrm{m} / \mathrm{z}$ : 1155.32 were also noted meaning the presence of tetramers trace. 
<smiles>Oc1cc(O)c2c(c1)OC(c1ccc(O)c(O)c1)C(O)C2</smiles><smiles>Oc1cc(O)c2c(c1)OC(c1ccc(O)c(O)c1)C(O)C2c1c(O)cc(O)c2c1OC(c1ccc(O)c(O)c1)C(O)C2</smiles><smiles>Oc1cc(O)c2c(c1)OC(c1ccc(O)c(O)c1)C(O)C2c1c(O)cc(O)c2c1OC(c1ccc(O)c(O)c1)C(O)C2c1c(O)cc(O)c2c1OC(c1ccc(O)c(O)c1)C(O)C2</smiles>

Fig. 7 : Structures of monomers, dimers and trimers of procyanidinol: (1): catechin (epicatechin); (2): example of catechin dimer (epicatechin); (3): example of catechin trimer (epicatechin).

These results suggest thus that condensed tannins widely present in the methanol fraction are partly responsible for the anti-inflammatory activity of the barks. Among which the most frequent oligomers are dimers and trimers. So catechin and/or epicatechin would be the main structural components of the tannins of Piliostigama reticulatum barks as such was the case with the proanthocyanidines of the pine barks : Pinus densiflora and Pinus thunbergii [21].

\section{CONCLUSION}

The barks of Piliostigma reticulatum are rich in tannins especially in proanthocyanidines. The latter would be responsible for their anti-inflammatory activity. It would therefore be interesting to assess their toxicity for better therapeutic use. It would also be important to fractionate this tannic fraction into monomers, dimers, trimers tetramers etc... and to assess the impact of the polymerization of the latter on the activity. This would require a preparatory analytic fractionation to obtain these different fractions in sufficient quantity for to re-evaluate the anti-inflammatory tests and thus to identify the activities synergies of the extract.

\section{REFERENCES}

[1] Maisuthisakul P, «Phenolic Constituents and Antioxidant Properties of some Thai Plants », in Phytochemicals - A Global Perspective of Their Role in Nutrition and Health, V. Rao, Éd. InTech, 2012.

[2] Wargovich M. J. Anticancer properties of fruits and vegetables. HortScience. 2000; 35 (4):573-575.

[3] Olusola A, Akomolafe S. F and Abayomi T. G. Antioxidant Potential of the Leaf Extract of Pilostigma Thonningii (Caesalpiniacea). J. Atoms and Molecules, 2013; 3(2):474-477

[4] Auddy B, Ferreira M, Blasina F, Lafon L, Arredondo F, Dajasb F, P.C. Tripathic, Seala T, Mukherjee B. Screening of antioxidant activity of three Indian medicinal plants, traditionally used for the management of neurodegenerative diseases. Journal of Ethnopharmacology, 2003; 84(2-3):131-138

[5] Latté K. P. et Kolodziej H. Antioxidant Properties of Phenolic Compounds from Pelargonium reniforme. Journal of Agricultural and Food Chemistry. 2004; 52 (15):4899-4902.

[6] Tabart J, Kevers C, Pincemail J, Defraigne J.O et Dommes J. Comparative antioxidant capacities of phenolic compounds 
measured by various tests. Food Chemistry. 2009 ; 113(4):1226-1233.

[7] Dieng S I M, Mathieu C., Sarr A. Diatta-Badji K. et Fall A D. Condensed Tannins Content and their Influence on the Antioxidant Activity of Bark Hydroethanol Extract of Piliostigma reticulatum (Dc) Hochst and its Fractions. Pharmacognosy Journal. 2020; 12(2):361-368.

[8] Aderogba A. M., Okoh E. K., Okeke I. N.et Olajide M. Antimicrobial and anti-inflammatory effects of Pilostigma reticulatum leaf extract. International journal of pharmacology. 2006; 2(1):70 -74.

[9] Yelemou B, Bationo B. A, Yameogo G, et Rasolodimby J. M. Gestion traditionnelle et usages de Piliostigma reticulatum sur le Plateau central du Burkina Faso. BOIS \& FORETS DES TROPIQUES. 2007; 291(291):55-66.

[10] Arbonnier M., Arbres, arbustes et lianes des zones sèches d'Afrique de l'Ouest. Editions Quae; 2009.

[11] Labourel G. et Péaud-Lenoel C. Separation par Chromatographie sur colonne de silice des glucofructosanes de la série inuline de D. P. entre 1 et 20.. Chem. zvesti ,1969; 23:765-769

[12] Yang C., Li D. et Wan X. Combination of HSCCC and Sephadex LH-20 methods: An approach to isolation and purification of the main individual theaflavins from black tea. Journal of Chromatography B. 2008; 861(1):140-144.

[13] Winter C. A, Risley E. A et Nuss G. W. Carrageenin-Induced Edema in Hind Paw of the Rat as an Assay for Antiinflammatory Drugs. Proceedings of the Society for Experimental Biology and Medicine. 1962; 111(3):544-547.
[14] Sene M. Barboza F S, Sarr A, Outouen D T, Wele A, Bassene E and Sy G Y. Analgesic and anti-inflammatory activity of methanolic fraction of total ethereal leaf extract of Annona senegalensis Pers. (Annonaceae). Afr. J. Pharm. Pharmacol. 2017; 11(8):120-124.

[15] Nariman F, Eftekhar F, Habibi Z. et Falsafi T. Anti-Helicobacter pylori Activities of Six Iranian Plants. Helicobacter. 2004; 9 (2):146-151.

[16] Ferreira D. et Slade D. Oligomeric proanthocyanidins: naturally occurring 0-heterocycles. Natural Product Reports. 2002; 19 (5):517-541.

[17] Bruneton J. Pharmacognosie, phytochimie, plantes médicinales (4e éd.), Tec et Doc. Paris, 2009.

[18] Macáková K, Kolečkář2 V, Cahlíková L, Chlebek J, Hošt’álková A, Kamil K, Daniel J and Lubomír Opletal. Tannins and their Influence on Health ", in Recent Advances in Medicinal Chemistry. 2014; 159-208.

[19] Kantz K. et Singleton V. L. Isolation and Determination of Polymeric Polyphenols Using Sephadex LH-20 and Analysis of Grape Tissue Extracts. Am J Enol Vitic. 1990; 41(3):223-228.

[20] Chen L.G. et Wang C.C. Preparative separation of oligostilbenes from Vitis thunbergii var. taiwaniana by centrifugal partition chromatography followed by Sephadex LH-20 column chromatography. Separation and Purification Technology. 2008; 66(1):65-70.

[21] Kim S. M, Kang S. W, Jeon J. S, et Um B. H. A comparison of Pycnogenol $®$ and bark extracts from Pinus thunbergii and Pinus densiflora: Extractability, antioxidant activity and proanthocyanidin composition. 2012; 6(14):2839-2849. 